\title{
Anatolia
}

An International Journal of Tourism and Hospitality Research

ISSN: 1303-2917 (Print) 2156-6909 (Online) Journal homepage: http://www.tandfonline.com/loi/rana20

\section{A comprehensive picture of the social media challenge for DMOs}

\section{Fulvio Fortezza \& Tonino Pencarelli}

To cite this article: Fulvio Fortezza \& Tonino Pencarelli (2018): A comprehensive picture of the social media challenge for DMOs, Anatolia, DOI: 10.1080/13032917.2018.1439759

To link to this article: https://doi.org/10.1080/13032917.2018.1439759

曲 Published online: 15 Feb 2018.

Submit your article to this journal $\widetilde{ }$

Q View related articles $\sqsubset$

View Crossmark data $־$ 


\title{
A comprehensive picture of the social media challenge for DMOs
}

\author{
Fulvio Fortezza a and Tonino Pencarelli ${ }^{\mathrm{b}}$ \\ ${ }^{a}$ Department of Economics and Management (DEM), University of Ferrara, Ferrara, Italy; ${ }^{b}$ Department of Economics, \\ Society and Politics (DESP), University of Urbino Carlo Bo, Urbino, Italy
}

\begin{abstract}
Scholars strongly agree that DMOs are hubs devoted to the production of memorable experiences. In the last few years, several authors have been pointing out that destinations are called to a major "paradigm shift" over the web 2.0 revolution. However, this remains a partially under-explored topic. We want to come to a comprehensive understanding of how, to what extent, and under what critical conditions social media can reshape DMOs' value processes. We opted for a multiple case study research method with a grounded-theory approach. Our analysis reveals enormous opportunities for social networks to directly and indirectly impact on the destination brand equity. This is a potential that DMOs are barely exploiting, however, mainly due to cultural issues.
\end{abstract}

\section{ARTICLE HISTORY}

Received 22 April 2017

Accepted 8 February 2018

\section{KEYWORDS}

Social media; DMOs; tourist experiences; brand equity; value

\section{Introduction}

As Kaplan and Haenlein (2010, p. 61) state, social media are "a group of Internet-based applications that build on the ideological and technological foundations of web 2.0, and that allow the creation and exchange of user-generated content". They are gaining pervasive importance, both in societies and markets, thus becoming an evermore important part of every organisation's media mix (Peters, Chen, Kaplan, Ognibeni, \& Pauwels, 2013). Nowadays, scholars strongly agree that the massive diffusion of web 2.0 is leading to a completely renewed playground for companies and other organizations. This mainly occurs because of the strong empowerment of users who want to, and can, interact with artists, politicians, brands and institutions as equal actors operating in the same network. This also applies to tourism (Buhalis \& Law, 2008; Sheehan, Vargas-Sánchez, Presenza, \& Abbate, 2016; Xiang \& Gretzel, 2010), where "the Internet has deeply transformed the manner in which travellers access information, plan for and book trips, and subsequently share their travel experiences" (Mariani, Di Felice, \& Mura, 2016).

In such an emotionally engaging industry like tourism, people are especially willing to participate. This is particularly evident when they are asked to create content, for example, when reviewing tourist services online. Moreover, tourists can get much more information on their own now, compared to the past, and they interact with each other, with Destination Marketing Organizations (DMOs), and with tourism companies as well.

All this calls for action even in DMOs as hubs devoted to the production of high-quality experiences which compete with other hubs on both national and international levels (Mariani, 2016; Neuhofern, Buhalis, \& Ladkin, 2012; Sainaghi, 2006). 
We do not aim to merely describe how DMOs utilize social networks, nor are we interested in testing specific hypotheses. Rather, we strive for a comprehensive understanding of how, to what extent, and under what critical conditions social media can reshape DMOs' path to value creation and dissemination. In other words, drawing on Buhalis and Law (2008), who pointed out that destinations are facing a major "paradigm shift" within the 2.0 digital challenge, we are interested in deepening the understanding of what that shift consists of and what the main prerequisites are for it to happen. This remains a partially under-explored topic (Fortezza \& Pencarelli, 2015; Hays, Page, \& Buhalis, 2013; Mariani et al., 2016; Roque \& Raposo, 2016; Xiang \& Gretzel, 2010) in the existing literature because, while we are aware of several issues, we do not have a complete picture, as yet.

We opted here for a case study research method, which is deemed suitable when taking into consideration a complex phenomenon that scholars do not have total control over yet, and when the "how" and "why" questions have not been addressed, either fully or in part (Yin, 1994). Accordingly, we used a grounded-theory approach (Gibson \& Hartman, 2014), which allows us to analyse a phenomenon in depth through the views of participants who are familiar with it (Glaser \& Strauss, 1967). In particular, we followed a constructivist logic, which provides the added value of having an interpretive understanding of phenomena (Matteucci \& Gnoth, 2017). In order to reach our research goal, we selected seven regional DMOs in Italy. Five of them were studied in a longitudinal way, while the last two were specifically selected to shed light on a particular aspect of interest which emerged in the analysis of the first cases.

\section{The possible role of DMOs as "intelligent hubs"}

Ritchie and Crouch (2003) point out that as the tourism industry becomes increasingly more competitive, destinations have to seek ways to advance their market position. In such a scenario, DMOs must have the ability to manage effective marketing tools in order to find the best ways to attract and retain tourists as well as to offer distinctive value (Buhalis, 2000). From this point of view, scholars strongly agree on the fact that tourism is a market and a social phenomenon which is intrinsically experiential. When visiting a destination, people expect to have a unique and memorable experience (Hays et al., 2013; Morgan, Elbe, \& de Esteban Curiel, 2009). This is a very complex experience (Neuhofer et al., 2012), firstly because it encompasses not only the narrow timeframe of the holiday time spent in a particular place, but also includes the wider timeframe of the pre-travel and post-travel phases. Moreover, it comes from multiple interactions and moments of truth with all the tourist providers of the destination, as well as with local inhabitants.

All this makes the role of DMOs both crucial and challenging. As Sheehan et al. (2016) argue, DMOs do not produce or own outright the destination's tourism product; instead, they are called to undertake the coordinating of the diverse and independent sectors of the local tourism industry and the promoting of the destination as a multifaceted whole. In a word, they must act as hubs (Bornhorst, Ritchie, \& Sheehan, 2010; Buhalis, 2000). It comes as no surprise that the matter of managing tourist destinations in the form of networks has received a great deal of attention in the last few years (Volgger \& Pechlaner, 2014). From this standpoint, scholars appear to be increasingly interested in ICTs as a source of knowledge generation and dissemination which can strongly help DMOs to manage and reinforce their "network of value" (Fuchs, Höpken, \& Lexhagen, 2014; Sheehan et al., 2016). For example, Schianetz, Kavanagh, and Lockington (2007) introduce the concept of "learning tourism destinations", based on the use of lifelong learning as an organising principle and social goal. Here, DMOs provide an infrastructure designed to collect new information, disseminate, process and apply gained knowledge, while creating possibilities for further learning and development to all stakeholders. Similarly, Racheria, Hu, and Hyun (2008) speak of "knowledge-based destinations", while Neuhofer et al. (2012) speak of "technology enhanced destinations". In this sense, knowledge technologies and processes are seen as an enabling factor for DMOs to implement innovative value processes (Buhalis \& Law, 2008), thus maximising the opportunities for tourism players to attract, satisfy, and retain visitors. 
However, although web 2.0 platforms do represent an important facet of new leading ICTs, the existing literature on destination marketing has so far scarcely considered them as possible tools that could help DMOs to enhance their role as "hubs". This is the reason why we want to bring this matter to the fore.

\section{Methodology}

\section{Why we chose the cross case method}

We consider our research focus a topic which needs a deeper and more comprehensive understanding. To this end, thick description, exploratory research, and comparative case analysis may be more suitable than quantitative methods (Birkinshaw, Brannen, \& Tung, 2011). We focused our research on regions because, in the chosen country, they are the real DMOs. This is based on the way the tourism industry is organised; here, DMOs interact, upstream, with the central government, and downstream, with the provinces and municipalities. We interviewed official social media teams and then analysed their daily activities, that is to say, we looked at what activities they perform and how they do them. For each DMO, we were also interested in discerning and understanding the most prominent formal and informal interactions occurring between the social media team and a number of key internal partners, especially those responsible for setting up tourism strategies and related planning processes, and those responsible for creating special tourist products in cooperation with local tourism operators. In the next few sections of the article, we do not mention the real name of the regions included in our study in order to freely report on what came out of the interviews. Our respondents would have otherwise been very afraid to reveal their real thoughts.

\section{How we selected the cases to study}

We made the selection of the cases to study by adopting a mixed sampling strategy (see Table 1), in accordance with the criteria provided by Patton (1990). We started our research with a pilot case (DMO1), which was selected by "convenience sampling", because of the pre-existing relationship between one of the authors of this article and the social media team of that region. Despite the convenience sampling, this case study shows some interesting features, which make it potentially information-rich. In fact, DMO1 is one of the most proactive destinations in the country we considered, with the most name recognition for places along the coast. Here, compared to other front-runner destinations, innovation in tourism usually occurs sooner. The pilot study allowed us to improve our analysis in several ways, as follows: it helped us choose the other cases, focus on the most relevant issues to deepen understanding, and refine the question guide for semi-structured interviews. Once the first step of the pilot case study analysis was started, we selected further cases following Patton's (1990) guidelines:

- we selected DMO2, a region which is immediately adjacent to the one in the pilot case. They closely resemble each other in terms of tourist offerings, territorial features, and cultural background. In this case, we followed a "homogeneity" criterion;

- we then studied DMO3, which was considered highly information-rich based on the observation of its social media activities and the suggestions made by the previous interviewees. Because of its similar features, we also included DMO4, as well as another case; the latter, however, decided to not take part in the research. Here, we opted for an "intensity case" sampling strategy;

- based on a "criterion" sampling strategy we then included DMO5 because this region is the most attractive, in terms of international tourist flows in the chosen country (http://www.enit.it/it/ studi.html, last access on 7 February 2018). We considered this kind of data to be an interesting proxy of the appeal of each region. With the analysis of DMO5 we aimed to enrich our study by taking into consideration one of the most internationally attractive Italian tourist destinations; 


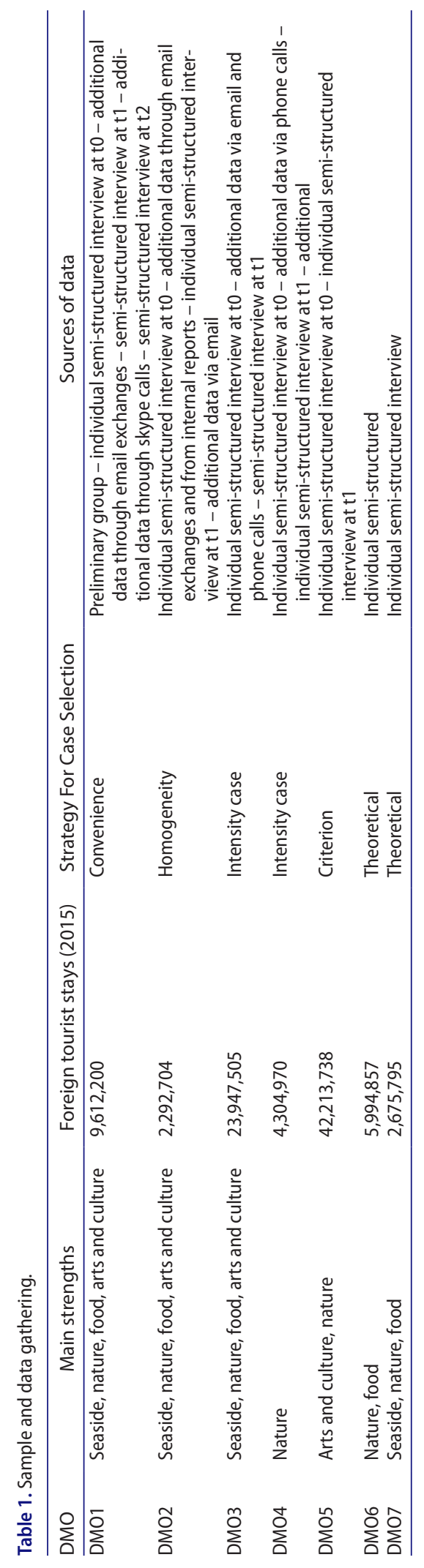


- finally, we included DMO6, following a "theoretical” sampling approach. Here, we needed to deepen the understanding of a hot topic, which partially arose in the analysis of the former cases. We selected DMO6 because of some secondary data which led us to think about this case as being information-rich. Unfortunately, however, we were not able to get the information we expected, thus we selected one more case, DMO7, which has been one of the best performing Italian touristic regions in the last few years.

Overall, we drew on the suggestions provided by Kuzel (1999), according to whom authors should remain flexible when choosing their cases, because the choice of the first case can affect the choice of the second and so on, and they should stop adding new cases when they reach the information saturation point for both evidence and alternative explanations. Ultimately, we collected seven case studies, which is a number consistent with analytical generalisation according to Eisenhardt (1989).

\section{How the cases were studied}

We studied our cases through semi-structured interviews which were repeated in different steps, from December 2014 to December 2016. This way, we aimed to understand the most relevant changes occurring in the social media activities of the DMOs we included in our sample (see Table 1), as well as to shed light on new interesting issues that we had not taken into consideration previously in a way consistent with the grounded theory view. This is the reason why, for each case, we carried out several rounds of analysis, of a greater or lesser number, based on how complex and information-rich it was. As for DMO1, because it was the pilot case study, we opted for a preliminary step of analysis through a group interview held with the entire social media team, in order to arrive at the "big picture" and understand what issues deserved deeper examination. Except for this preliminary interview, the others were carried out only with the directors of each social media team included in the sample. As for cases DMO6 and DMO7, these were the only ones that we analysed through a single round of interviews. This occurred because they were included in the study in order to reach theoretical saturation (Creswell, 2007). When needed, each interview was enriched or supplemented with email exchanges and/or brief skype or phone calls. When we studied DMO2 we could also rely on secondary data from internal reports and notes.

The average length of the interviews varied from a maximum of four hours (preliminary group interview with DMO1) to a minimum of one and half hours (individual semi-structured interview with the social media leader of DMO6). Each of them was recorded and fully transcribed by one of the authors to result in approximately seventy single-spaced pages' worth of material. Subsequently, the contents were manually and flexibly coded by both authors according to emergent themes. From this point of view, as Matteucci and Gnoth (2017) state, the grounded-theory approach demands an iterative research process; thus, data analysis starts long before all the data is fully collected and implies a constant comparison among all the cases taken into consideration.

\section{Results}

\section{Resilience}

One important characteristic that nearly all of the interviewed social media teams showed was resilience, which can be interpreted here as the ability to deal with and manage complexity. Actually, the main challenge for our informants does not simply lie in the complexity of the activities they manage, but rather, in the relationship between such complexity, on one hand, and the instability and scarcity of available resources (in particular specialised human resources), on the other. From the point of view of organisation and resources, all of the teams included in the study continually undergo changes. Therefore, they tend to get reconfigured as, on the one side, the social strategies of DMOs evolve and, on the other side, the regions find new ways to employ more professionals. 
There are some cases (DMO1, DMO2 and DMO7) where the social media teams are entirely or mostly made up of independent professionals. Other cases (DMO3, DMO4 and DMO5), instead, primarily consist of internal professionals; usually, they not only manage social media activities but also work on the overall digital communication of the DMO. Moreover, in these cases additional independent professionals join the teams when DMOs can access ad hoc public funds. However, these always are time-limited collaborations, thus resulting in an unstable support to the needs of the DMOs. In addition, there are also cases (DMO2, DMO5 and DMO6) where social media teams are supported by internal DMO human resources who do not, however, possess specialised skills in the area of social media activities. This is but a stopgap means for certain DMOs to somehow deal with the increasing amount of work they encounter every day in the web 2.0 context.

From this standpoint, we must bear in mind two main aspects, the first one being the endless evolution of the social media environment, which entails continuous changes in the features of the existing social networks, the rise of new social networks, and the decline of others. The second aspect is that social media demand the continuous creation of ad hoc content, which has to be targeted to specific audiences and properly scheduled in the best time slots. It must also be noted that when a $\mathrm{DMO}$ creates one or more official accounts to represent the destination in the social media environment, people expect to participate in some way.

Users really love to interact with us, to be involved in our activities, to have a role. We must be there and play, always. (DMO2)

Such a (nearly) never-ending communication process also requires the ability to manage online interactions which can strongly influence the reputation of destinations. This is clearly a completely different scenario compared to the one where places are promoted in the traditional way.

Overall, the interviewed social media teams seemed to be mistrustful of the DMOs they are part of because, in their minds, the top echelons appear incapable of really understanding the complexity of their work or all its potentialities.

Politicians do not understand how much work we have to do everyday to carry out our activities. It appears to them as though it is too easy. (DMO3)

This is strictly tied to the issue of value measurement, since proper metrics and tools would probably help decision-makers to better appreciate how social media can impact on the competitive advantage of the destination. In our sample, with the exception of DMO5 and DMO6, which do not perform any kind of measurement, the other DMOs we studied use the most common metrics offered by each social network. However, our informants pointed out that they would prefer to rely on wider-ranging tools in order to estimate the real impact that social media activities can have in terms of tourism enhancement.

If you have any idea about how to build an effective method to measure the results we can reach, please let us know immediately! What we really need is a way to "certify" how much added value is generated by one single euro which is properly spent on the 2.0 digital eco-system. (DMO3)

Another important point we must take into account is that social media teams are profoundly influenced by the political shifts that take place within DMOs. This, also, exposes social media activities to a certain degree of risk of instability.

We performed outstandingly with the previous administration. The strategic orientation of the Region was very clear and we were asked to play a relevant role in order to accomplish it. They always kept our suggestions in mind when making their choices. With new rulers everything has changed. Nobody is interested in what we did in the past and how we did it. (DMO7)

As for how the aforementioned resilience manifests itself, two main facets, i.e. a sort of "self-empowerment" by social media teams and incrementalism merit attention.

Despite the resource constraints, social media teams are very committed to the potentialities of social media activities and strive to play more and more of a leading role within the overall communication strategy of the DMO, aside from the official tasks and hierarchy defined by the DMO itself. 
We could do much more if we were supported. So many times it happens that we get involved in lots of powerful activities, putting in over and above the standard working hours, and even involving external unofficial resources that may be of help. We are driven by passion for what we do everyday and have the absolute awareness that we can significantly enhance the competitiveness of our territories. (DMO4)

In essence, the social media teams under scrutiny tend to fine-tune their efforts by incremental steps, although they do have a clear idea of how they could enhance the region's image. This, for example, affects the choice of the social networks to enter. All the interviewed social media teams consider Facebook a "must", so they all have their Facebook fan pages at the very least in the native language and in English, too, while some of them (DMO1, DMO2, DMO3 DMO4) also have other languages available, based on the tourist markets they are more interested in. Content creation in different languages is one of the tasks where social media teams are more self-organised, by involving mostly freelancers (DMO1) or part-time collaborators (DMO3). Twitter is the next most used social network by the social media teams. They run it in a complimentary way to Facebook. Even the social networks based on images are highly appreciated, especially Instagram, which offers so many chances to engage local communities in offline activities. Lastly, among the most appreciated social networks we find blogs, even though not all the social media teams use them, because this tool is very challenging and time-consuming.

\section{Co-creation and emotional involvement}

The interviewed DMOs do not merely choose which social networks to join. In fact, the most proactive among them are also consistently engaged in designing initiatives such as web contests or even offline events able to boost the awareness and positioning of their places by primarily involving locals but also influencers of their online audiences within experiential and non-conventional activities. The key point here is the collaborative creation of content and emotionally engaging experiences with people.

For example, DMO1 asks people who are living or were born in the region to play a role, in three very creative ways. The first initiative aims to improve the Wikipedia entries related to the region, in order to allow for a better representation of its main features. The second initiative consists of a sort of online collective cookbook designed to gather and share the principle, traditional local dishes, with the many different versions which come from specific places or families. The third initiative is particularly noteworthy. Through the web, citizens can apply to host the social media team for Sunday lunch. This is a real shared experience, where the guests are asked to take an active role, from obtaining the ingredients to actually preparing and cooking the meal. Each step is described in real time.

Other initiatives (DMO 1, DMO2 and DMO7) consist of offering people chances to live memorable offline experiences within the region. In such cases, social media teams usually target bloggers, who are given the possibility to spend their holiday time in the region for free. The DMOs expect them to really enjoy their experiences and to then tell their audiences, thus resulting in a high-value word of mouth communication method.

However, even if content co-creation is an intriguing avenue for DMOs to generate emotional engagement, it is not always a viable solution. As the social media leader of DMO2 pointed out, "the interactions with users offer so many opportunities, but they need to be carefully addressed and managed". From this point of view, DMOs (in our sample, DMO3 acts this way) can also choose to involve just professional or semi-professional users, above all for photos, in the co-creation process.

\section{Authenticity and storytelling}

The prominent feature of the communication run by the best performing social media teams is authenticity (as an approach), which results in narratives (as a tool) related to the lesser known aspects of places, their cultural backgrounds, history, and local customs. This is connected to the previous point, because even content co-creation is mainly based on authentic storytelling that makes it possible to 
spotlight even the smallest places, too, those which are usually ignored in traditional destination branding schemes.

People usually do not expect our places to be so intriguing. We can see every day how astonished people are when they discover the many different facets of our places. (DMO4)

This also affects international tourist flows, at least for the best-equipped social media teams in our sample (DMO1, DMO2, DMO3, and DMO4). They base their editorial choices and scripts on a limited number of themes which are consistent, upstream, with the positioning aimed for by the DMO and, downstream, with the top local tourist products and attractions.

This appeals even to local inhabitants, because these engaging narratives help them discover places, events, and other opportunities for leisure time activities which they might otherwise have never been aware of. This can also enhance their feelings of pride and belonging to places and help to sustain their role as possible tourist experience co-creators.

We are delighted to see our countrymen who feel proud when their homeland is spotlighted and celebrated. (DMO7)

Local inhabitants are important for us. They can be 'internal tourists'. Most importantly, they must be aware of their role in promoting the places they live in. (DMO4)

One crucial issue which emerges here is the coordination between the social media activities undertaken by DMOs and the ones run by each local destination at the downstream level. Without the proper attention to this coordination, there is a clear risk of ending up with an overall inconsistent narrative. In this sense, social media teams tend to design a generally attractive framework for communication on social networks, to which they will try to bring the best content created day by day at downstream levels. The interviewed social media teams look for many different solutions in their effort to facilitate the coordination with peripheral teams, although this usually does not follow structured rules.

We arrange weekly meetings where we offer coaching to anyone who needs it. For example, recently we met with the head of communication of a well-known cultural heritage site. (DMO1)

This way of highlighting and celebrating the soul and the peculiarities of a destination can help companies of the local tourist system to boost their bookings, especially when it is combined with the booking offers available through the DMO websites.

Our destination can greatly benefit from our work in terms of greater tourist flows. However, in order for this to really happen, the act of telling about our places and that of boosting bookings must get closer. (DMO4)

From this point of view, the opportunities for the local tourism system can further expand, based on how and to what extent DMOs cooperate with tourism companies. For example, DMO7 systematically uses themed calls to action for tourist operators (hotels, restaurants, shops and so on), who can access the DMO's website and insert offerings which fit the theme being sent out by the DMO. On this point, except for DMO5 and DMO6 where social media teams have a very limited role, the other informants appeared to be very confident.

Let's consider the matter of 'detox holidays', which is one of the most recurring themes on our 2.0 web spaces. Lots of people would like to find this kind of offering in our region. However, we do not have dedicated solutions at the moment. It's not so easy for us to codify and direct these kinds of information to our colleagues who deal with tourist products. (DMO1)

We are not involved in decisions about tourist products. There is a specialized team devoted to that and we never interact with them. That's a real pity! (DMO5)

From this point of view, among the cases we took into consideration the most interesting appears to be the one of DMO4. Here, the rulers set up the strategic directions for the development of the destination in the medium-to-long run. Then, a specialised independent consulting company translates them into plans and, finally, a dedicated internal team of the DMO responsible for tourist products works on enhancing the tourist offering by closely cooperating with the social media team.

Our interviewees pointed out that to implement such a bottom-up destination marketing process it is necessary to act very deliberately, to avoid just following sensations, and to aim for structured insights supported by the proper resources. 
We would need suitable tools because intuition is not enough! (DMO7)

Everybody says that they want to capitalize on the information generated by social media. This is hardly ever true. We had set up a well-structured method for data monitoring, but we had to give it up because of the scarcity of resources. (DMO3)

\section{Conclusion and implications}

Our analysis reveals the outstanding opportunities that social networks can offer on a day-by-day basis to positively influence the generation of value for a destination.

Our findings appear to be consistent with several themes which emerged here and there in other studies on this topic which considered different kinds of DMOs, for example, national rather than regional DMOs, in many different countries. Some specific insights have emerged from this study. Overall, we offer a comprehensive representation of the 2.0 digital challenge for DMOs.

Social media activities can powerfully boost the entire process which leads to the creation and promotion of memorable tourist experiences. This refers, not to communication alone, but to something that is potentially much more pervasive and even challenging for DMOs. Not only can social media activities be considered a special (but complex) way to communicate with targeted audiences in a highly emotionally engaging manner, but they are also a relevant part of a new scenario in the value processes of destinations.

In order to conceptualise how social media marketing can support DMOs in acting as hubs in the tourism industry, we recall the notion of destination brand equity (Herrero, San Martín, Garcia de los Salmones, \& Collado, 2016; Pike \& Bianchi, 2013). It describes how much distinctive value the destination brand adds to the offering provided by the whole local tourism system.

The social media activities undertaken affect the destination brand equity in both a direct and an indirect way. A direct impact on destination brand equity refers to those effects which are more strictly tied to social media activities, while an indirect impact refers to those factors which can lead the local tourism system to better perform in a subsequent, incremental fashion (see Figure 1).

In order to clarify how the social media activities directly influence the destination brand equity we recall what Aaker (1991) posits, that is to say, that brand equity is made of brand awareness, perceived quality, brand associations and brand loyalty.

From the standpoint of brand awareness, our analysis revealed some important advantages of social media marketing activities compared to traditional place marketing schemes. First of all, they give DMOs the chance to consistently get in touch with and engage many different audiences. For example, they make it possible to reach international tourist flows with relatively inexpensive initiatives that just cover the influencers' travel, food, and accommodation expenses. Moreover, the continual, dynamic and pervasive communication which is carried out through social networks allows even the destination's less-known sights and attractions to reap the benefits of being in the spotlight; they would otherwise not have much visibility of any significance. This leads to a more comprehensive representation of the destination which rarely occurs when DMOs use traditional communication channels, such as standard advertising or tourism fairs.

Social media activities also affect perceived quality and brand associations for tourists. In this sense, one main driver emerges: (authentic) storytelling (Woodside, Sood, \& Miller, 2008). It allows for a deep communication and activates a delight response by users (Pera, 2014). It also results in strong associations by building connections between the themes on which narratives are based and the main tourist attractions of the destination. As a consequence, it becomes easier to reach specific kinds of tourists, including communities of enthusiasts (e.g. motor or food lovers), even at the international level. Social networks also lend themselves well to portraying all of the many different nuances of a destination, by creating step by step an overall dynamic representation based on authenticity (Pine \& Gilmore, 2007). Moreover, social media activities can emotionally engage the local inhabitants, too, as they can discover or rediscover relevant aspects of the history, traditions, and cultural background of the places they live in. This can reinforce their sense of belonging and awareness of how they can 


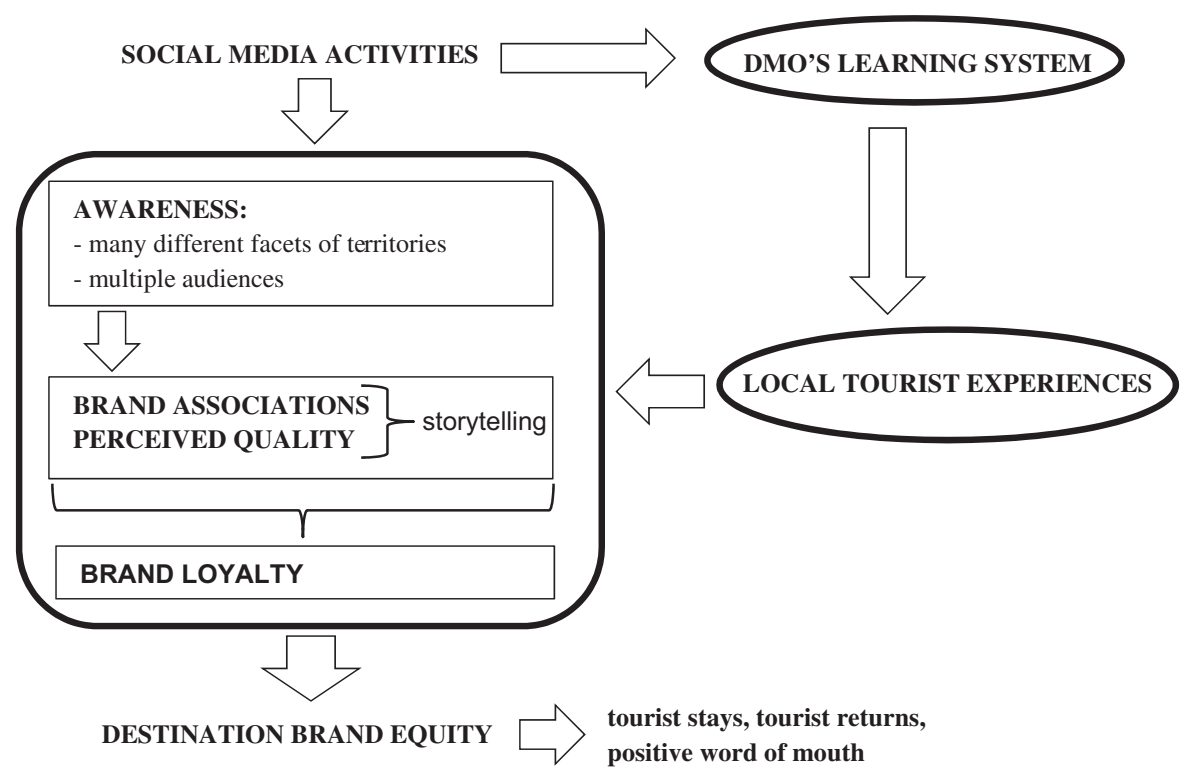

Figure 1. The impact of social media activities on destination brand equity. Source: our own representation, inspired by Aaker, 1991.

play a more effective role in the production of memorable experiences for tourists (Bornhorst et al., 2010). For example, this occurs when they partake in local folkloristic events (e.g. historical reenactments) as active players.

All of this combined can affect the destination brand loyalty by recalling the most engaging emotions experienced by tourists. They, in turn, will be encouraged to share their impressions or even to visit the destination again to discover new places and sights (Neuhofer et al., 2012).

The indirect impact of social media activities on destination brand equity mainly refers to the possibility for DMOs to get useful insights from web 2.0 channels as a significant source of competitive advantage (Sheehan et al., 2016). This results in increased chances for the players of the local tourist system to innovate their offerings. In this sense, DMOs play a crucial role as previous studies have highlighted (Gretzel, Fesenmaier, Formica, \& O’Leary, 2006; Hays et al., 2013; Sainaghi, 2006). From this standpoint, the 2.0 digital challenge is primarily a cultural challenge for DMOs (Gretzel et al., 2006; Racheria et al., 2008). It has to do with adopting the right mindset in order to see and understand a completely new playground (Hays et al., 2013), which is less based on pre-packed and top-down "solutions" (i.e. tourist products and communication campaigns) and is more based on an increasing degree of co-evolution with demand (Neuhofer et al., 2012). This brings to the fore the challenge of big data (Fuchs et al., 2014; Wang, Park, \& Fesenmaier, 2012), of which social networks can be a relevant source.

Such an approach can lead the entire destination towards a more dynamic way of competing on the market. Those who work on social networks every day clearly perceive this potential (Hays et al., 2013). In order for all of this to happen, three additional important issues need to be addressed. They are as follows:

- the allocation of resources which adequately satisfy the need for steady and strong support for digital teams (Mariani et al., 2016);

- the internal relationships within DMOs between the ones who work on tourist products and the ones who work on digital communication;

- the set-up of comprehensive and effective ICT platforms as support for the entire tourist system (Fuchs et al., 2014). 
Our study also suggests some future research directions. Firstly, it would be useful to consider the perspective of users in order to test to what extent specific social media activities or tools influence specific dimensions of the destination brand equity. Secondly, more attention should be paid to how the actual additional value which comes out of social media activities could be measured from a systemic and multistakeholder viewpoint (Peters et al., 2013). Lastly, as a related topic, it would be interesting to study how different institutional DMO structures can affect the aforementioned systemic performance.

\section{Disclosure statement}

No potential conflict of interest was reported by the authors.

\section{Notes on contributors}

Fulvio Fortezza is an associate professor of Marketing and International Marketing at the Department of Economics and Management of the University of Ferrara. His research activity is mainly about experience economy in tourism, collaborative consumption, and happiness.

Tonino Pencarelli is a full professor of Business Management at the Department of Economics, Society and Politics of the University of Urbino Carlo Bo. His research activity is mainly about destination branding, experience economy in tourism, and service marketing.

\section{References}

Aaker, D. A. (1991). Managing brand equity. New York, NY: The Free Press.

Birkinshaw, J., Brannen, M. Y., \& Tung, R. L. (2011). From a distance and generalizable to up close and grounded: Reclaiming a place for qualitative methods in international business research. Journal of International Business Studies, 42, 573-581. doi: 10.1057/jibs.2011.19

Bornhorst, T., Ritchie, J. R. B., \& Sheehan, L. (2010). Determinants of tourism success for DMOs \& destinations: An empirical examination of stakeholders' perspectives. Tourism Management, 31(5), 572-589. doi:10.1016/j. tourman.2009.06.008

Buhalis, D. (2000). Marketing the competitive destination of the future. Tourism Management, 21(1), 97-116. doi:10.1016/ S0261-5177(99)00095-3

Buhalis, D., \& Law, R. (2008). Progress in information technology and tourism management: 20 Years on and 10 years after the Internet. The state of eTourism research. Tourism Management, 29(4), 609-623. doi:10.1016/j.tourman.2008.01.005

Creswell, J. W. (2007). Qualitative inquiry \& research design: Choosing among five approaches. Thousand Oaks, CA: Sage.

Eisenhardt, K. M. (1989). Building theories from case study research. The Academy of Management Review, 14(4), 532-550.

Fortezza, F., \& Pencarelli, T. (2015). Potentialities of Web 2.0 and new challenges for destinations: Insights from Italy. Anatolia, 26(4), 563-573. doi 10.1080/13032917.2015.1040813

Fuchs, M., Höpken, W., \& Lexhagen, M. (2014). Big data analytics for knowledge generation in tourism destinations - A case from Sweden. Journal of Destination Marketing \& Management, 3(4), 198-209. doi:10.1016/j.jdmm.2014.08.002

Gibson, B., \& Hartman, J. (2014). Rediscovering grounded theory. London: Sage.

Glaser, B. G., \& Strauss, A. L. (1967). The discovery of grounded theory: Strategies for qualitative research. Chicago, IL: Aldine.

Gretzel, U., Fesenmaier, D. R., Formica, S., \& O’Leary, J. T. (2006). Searching for the future: Challenges faced by destination marketing organizations. Journal of Travel Research, 45(2), 116-126. doi:10.1177/0047287506291598

Hays, S., Page, S., \& Buhalis, D. (2013). Social media as a destination marketing tool: Its use by national tourism organisations. Current Issues in Tourism, 16(3), 211-239. doi:10.1080/13683500.2012.662215

Herrero, A., San Martín, H., Garcia de los Salmones, M., \& Collado, J. (2016). Examining the hierarchy of destination brands and the chain of effects between brand equity dimensions. Journal of Destination Marketing \& Management, available online 20 May 2016. doi: 10.1016/j.jdmm.2016.05.001

Kaplan, A. M., \& Haenlein, M. (2010). Users of the world, unite! The challenges and opportunities of social media. Business Horizons, 53(1), 59-68. doi:10.1016/j.bushor.2009.09.003

Kuzel, A. J. (1999). Sampling in qualitative inquiry. In B. F. Crabtree \& W. L. Miller (Eds.), Doing Qualitative Research (pp. 33-45). Thousand Oaks, CA: Sage.

Mariani, M. M. (2016). Coordination in inter-network co-opetitition: Evidence from the tourism sector. Industrial Marketing Management, 53, 103-123. doi:10.1016/j.indmarman.2015.11.015 
Mariani, M. M., Di Felice, M., \& Mura, M. (2016). Facebook as a destination marketing tool: Evidence from Italian regional destination management organizations. Tourism Management, 54, 321-343. doi:10.1016/j.tourman.2015.12.008

Matteucci, X., \& Gnoth, J. (2017). Elaborating on grounded theory in tourism research. Annals of Tourism Research, 65, 49-59. doi:10.1016/j.annals.2017.05.003

Morgan, M., Elbe, J., \& de Esteban Curiel, J. (2009). Has the experience economy arrived? The views of destination managers in three visitor-dependent areas. International Journal of Tourism Research, 11(2), 201-216. doi:10.1002/ jtr.719

Neuhofern, B., Buhalis, D., \& Ladkin, A. (2012). Conceptualising technology enhanced destination experiences. Journal of Destination Marketing \& Management, 1(1/2), 36-46. doi:10.1016/j.jdmm.2012.08.001

Patton, M. Q. (1990). Qualitative evaluation and research methods. Newbury Park: Sage.

Pera, R. (2014). Empowering the new traveller: Storytelling as a co-creative behaviour in tourism. Current Issues in Tourism, available online 23 December 2014. doi: 10.1080/13683500.2014.982520

Peters, K., Chen, Y., Kaplan, A. M., Ognibeni, B., \& Pauwels, K. (2013). Social media metrics - A framework and guidelines for managing social media. Journal of Interactive Marketing, 27(4), 281-298. doi:10.1016/j.intmar.2013.09.007

Pike, S., \& Bianchi, C. (2013). Destination brand equity for Australia: Testing a model of CBBE in short-haul and longhaul markets. Journal of Hospitality and Tourism Research, 10(10), 1-21. doi:10.1177/1096348013491604

Pine, B. J., II, \& Gilmore, J. H. (2007). Authenticity: What consumers really want. Boston, MA: Harvard Business School Press.

Racheria, P., Hu, C., \& Hyun, M. Y. (2008). Exploring the role of innovative technologies in building a knowledge-based destination. Current Issues in Tourism, 11(5), 407-428. doi:10.1080/13683500802316022

Ritchie, J. R. B., \& Crouch, G. (2003). The competitive destination: A sustainable tourism perspective. Cambridge: CABI.

Roque, V., \& Raposo, R. (2016). Social media as a communication and marketing tool in tourism: An analysis of online activities from international key player DMO. Anatolia, 27(1), 58-70. doi:10.1080/13032917.2015.1083209

Sainaghi, R. (2006). From contents to processes: Versus a dynamic destination management model (DDMM). Tourism Management, 27(5), 1053-1063. doi:10.1016/j.tourman.2005.09.010

Schianetz, K., Kavanagh, L., \& Lockington, D. (2007). The learning tourism destination: The potential of a learning organization approach for improving the sustainability of tourism destinations. Tourism Management, 28(3), 14851496. doi:10.1016/j.tourman.2007.01.012

Sheehan, L., Vargas-Sánchez, A., Presenza, A., \& Abbate, T. (2016). The use of intelligence in tourism destination management: An emerging role for DMOs. International Journal of Tourism Research, available online 16 February 2016. doi: $10.1002 /$ jtr.2072

Volgger, M., \& Pechlaner, H. (2014). Requirements for destination management organizations in destination governance: Understanding DMO success. Tourism Management, 41, 64-75. doi:10.1016/j.tourman.2013.09.001

Wang, D., Park, S., \& Fesenmaier, D. R. (2012). The role of smartphones in mediating touristic experience. Journal of Travel Research, 51(4), 371-387. doi:10.1177/0047287511426341

Woodside, A. G., Sood, S., \& Miller, K. E. (2008). When consumers and brands talk: Storytelling theory and research. Psychology \& Marketing, 25(2), 97-145. doi:10.1002/mar.20203

Xiang, Z., \& Gretzel, U. (2010). Role of social media in online travel information search. Tourism Management, 31(2), 179-188. doi:10.1016/j.tourman.2009.02.016

Yin, R. K. (1994). Case study research: Design and methods. London: Sage.

\section{Web sources}

ENIT. (2018). Il turismo straniero in Italia. Retrieved February 7, 2018, from ENIT website: http://www.enit.it/it/studi. html 